\title{
Deep brain stimulation affects conditioned and unconditioned anxiety in different brain areas
}

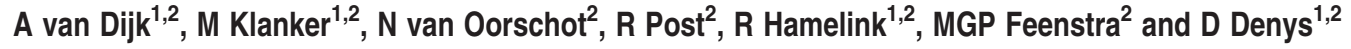

Deep brain stimulation (DBS) of the nucleus accumbens (NAC) has proven to be an effective treatment for therapy refractory obsessive-compulsive disorder. Clinical observations show that anxiety symptoms decrease rapidly following DBS. As in clinical studies different regions are targeted, it is of principal interest to understand which brain area is responsible for the anxiolytic effect and whether high-frequency stimulation of different areas differentially affect unconditioned (innate) and conditioned (learned) anxiety. In this study, we examined the effect of stimulation in five brain areas in rats (NAc core and shell, bed nucleus of the stria terminalis (BNST), internal capsule (IC) and the ventral medial caudate nucleus (CAU)). The elevated plus maze was used to test the effect of stimulation on unconditioned anxiety, the Vogel conflict test for conditioned anxiety, and an activity test for general locomotor behaviour. We found different anxiolytic effects of stimulation in the five target areas. Stimulation of the CAU decreased both conditioned and unconditioned anxiety, while stimulation of the IC uniquely reduced conditioned anxiety. Remarkably, neither the accumbens nor the BNST stimulation affected conditioned or unconditioned anxiety. Locomotor activity increased with NAC core stimulation but decreased with the BNST. These findings suggest that (1) DBS may have a differential effect on unconditioned and conditioned anxiety depending on the stimulation area, and that (2) stimulation of the IC exclusively reduces conditioned anxiety. This suggests that the anxiolytic effects of DBS seen in OCD patients may not be induced by stimulation of the NAC, but rather by the IC.

Translational Psychiatry (2013) 3, e289; doi:10.1038/tp.2013.56; published online 30 July 2013

\section{Introduction}

Deep brain stimulation (DBS) of the nucleus accumbens (NAc), ventral striatum/ventral capsule and the anterior internal capsule (IC) has proven to be an effective treatment for therapy-refractory obsessive-compulsive disorder (OCD) ${ }^{1-3}$ Clinical observations show that in particular anxiety symptoms decrease rapidly with stimulation. ${ }^{1-3}$ Interestingly, our clinical observations show that reduction of anxiety in OCD patients is restricted to the symptomatic fear associated with their obsessions and is not related to unconditioned anxiety (innate fears) or general anxiety, suggesting a focused effect of DBS on conditioned anxiety (learned fear). Conditioned anxiety in animals is elicited when a neutral stimulus is associated with a fearful event, for example, by pairing the stimulus with an electric shock while unconditioned anxiety is described as a natural behavioural reaction to a fear-evoking situation (for example, heights or predators) at a particular moment of time..$^{4-6}$ On the basis of clinical findings, we hypothesize that stimulation of the NAc uniquely affects conditioned anxiety and not unconditioned anxiety.

This study examines the effect of stimulation in five brain areas (NAc core and shell, the bed nucleus of the stria terminalis (BNST), the IC and the ventral medial caudate nucleus $(\mathrm{CAU}))$. These five brain areas are chosen on grounds of their use in human DBS studies. We used two specific behavioural paradigms for rodents to test the effect of stimulation on anxiety. First, we used the elevated plus maze (EPM) to test the effects on unconditioned anxiety. In the EPM test, a conflict is created between the natural behaviour to explore novel environments and the natural fear of heights and open spaces. ${ }^{7}$ Second, we used the Vogel conflict test (VCT), to test for conditioned anxiety, which is based on the conflict that water deprived rats experience when a previously acquired drinking response is 'punished' by a mild foot shock. ${ }^{8}$ In addition, we used an activity metric to investigate the effect of stimulation on general locomotor behaviour in a novel environment.

\section{Materials and methods}

Subjects. Male Wistar rats (250-350 g, Harlan, Boxmeer, The Netherlands, the NAc core and NAc shell group; Charles River, Sulzfeld, Germany, the BNST, IC and CAU group) were housed socially (2-4 animals per cage) in a temperature- and humidity-controlled vivarium with a 12-h reversed light-dark cycle $\left(20^{\circ} \mathrm{C}\right.$, lights off 0700 , on 1900 hours) and were provided with food and water ad libitum. Rats were handled regularly for 7 days before surgery by the experimenter. In total, there were four consecutive experimenters, two for the NAc core and NAc shell group and two for the BNST, IC and CAU group. The study was conducted

\footnotetext{
${ }^{1}$ Department of Psychiatry, Academic Medical Center University of Amsterdam, Amsterdam, The Netherlands and ${ }^{2}$ Netherlands Institute for Neuroscience, Institute of the Royal Netherlands Academy of Arts and Sciences, Amsterdam, The Netherlands

Correspondence: Dr A van Dijk, Neuromodulation and Behaviour, NIN, IA 2-130, Meibergdreef 47, 1105 BA Amsterdam, The Netherlands or Professor D Denys, Department of Psychiatry, Academic Medical Center, University of Amsterdam, PA.2-179, PO Box 75867, 1070 AW Amsterdam, The Netherlands.

E-mail: addyvandijk@gmail.com or ddenys@gmail.com

Keywords: anxiety; deep brain stimulation; elevated plus maze; OCD; Vogel conflict test

Received 3 May 2013; accepted 25 May 2013
} 
in accordance with governmental guidelines for the care of laboratory animals and approved by the Animal Experimentation Committee of the Royal Netherlands Academy of Arts and Sciences.

Surgery. On the day of surgery, the rats were anaesthetized with intramuscular Hypnorm $\left(0.22 \mathrm{mg} \mathrm{kg}^{-1}\right.$ fentanyl citrate and $7 \mathrm{mg} \mathrm{kg}^{-1}$ fluanisone, VetaPharma, Leeds, UK), subcutaneous Dormicum $\left(1.5 \mathrm{mg} \mathrm{kg}^{-1}\right.$ midazolam, Roche, Woerden, The Netherlands) was given for muscle relaxation and lidocaine as a local anaesthetic on the skull. The animals were then placed in a Kopf stereotactic apparatus (Kopf Instruments, Tujunga, CA, USA) and kept at a constant temperature of $36.5^{\circ} \mathrm{C}$. Two bipolar electrodes ${ }^{9}$ consisting of two twisted platinum/iridium wires with one pole $500 \mu \mathrm{m}$ ventral to the other were bilaterally implanted into either the NAc core $(A+1.3 \mathrm{~mm}, \mathrm{~L} \pm 2.0 \mathrm{~mm}, V 7.8 \mathrm{~mm})$, the NAc shell $(A+1.5 \mathrm{~mm}, \mathrm{~L} \pm 0.9 \mathrm{~mm}, \mathrm{~V} 7.3$ ), the BNST (dorsal pole medial, $A-0.45 \mathrm{~mm}, \mathrm{~L} \pm 1.5 \mathrm{~mm}, \mathrm{~V} 7.2$ ), the IC (dorsal pole anterior, $A-0.8 \mathrm{~mm}, \mathrm{~L} \pm 2.1 \mathrm{~mm}, \mathrm{~V} 6.8$ ) or the $\mathrm{CAU}$ (dorsal pole medial, $A+1.2 \mathrm{~mm}, \mathrm{~L} \pm 1.7 \mathrm{~mm}, \mathrm{~V} 6.8$ ). The coordinates are relative to bregma according to Paxinos and Watson. ${ }^{10}$ The electrodes were fixed to the skull surface with three stainless steel screws and dental acrylic cement. Rats were given subcutaneous finadyne $\left(5 \mathrm{mg} \mathrm{kg}^{-1}\right.$ flunixin, Schering-Plough, Oss, The Netherlands) postoperatively for pain management and were then housed in individual cages.

Experiments. After a recovery period of 7 days, behavioural experiments were performed over a period of 2 weeks during the animal's dark cycle. To find out what the effect of stimulation was on locomotor activity, an activity test was performed (see Supplementary Material). This was followed 1 day later by the test for unconditioned anxiety using the EPM. In the second week, the test for conditioned anxiety using the VCT paradigm was carried out (see Table 1). The control groups of the NAc core, the NAc shell and the CAU group had their electrode implanted in the same target area as the stimulated group. For the VCT, the control group of the NAc core and the NAc shell were combined because of technical problems surrounding the set up of the VCT. The BNST and the IC group had a joint control group in which the electrodes were implanted into the IC or the BNST. Stimulation of the rats was performed using a WPI Digital Stimulator (model DS8000, World Precision Instruments, Sarasota, FL, USA) and WPI Isolator (model DLS100) connected to a four-channel commutator (Plastics One, Roanoke, VA, USA) allowing unrestricted movement of the animals. A rat was either sham stimulated, stimulated with $200 \mu \mathrm{A}$ or with $300 \mu \mathrm{A}(120 \mathrm{~Hz}$, biphasic, pulse width $80 \mu \mathrm{s})$.

Table 1 Overview of the behavioral protocol

\begin{tabular}{llllll}
\hline Day 1 & Day 2 & Day 5 & Day 6 & Day 7 & Day 8 \\
\hline $\begin{array}{lllll}\text { Activity } \\
\text { test }\end{array}$ & EPM & $\begin{array}{l}\text { Water } \\
\text { restriction }\end{array}$ & $\begin{array}{l}\text { Water } \\
\text { restriction } \\
\text { introduction } \\
\text { phase }\end{array}$ & $\begin{array}{l}\text { Water } \\
\text { restriction } \\
\text { adaptation } \\
\text { test }\end{array}$ & $\begin{array}{l}\text { Water } \\
\text { restriction }\end{array}$ \\
& & & & & \\
\hline
\end{tabular}

Abbreviations: EPM, elevated plus maze; VCT, Vogel conflict test.
Elevated plus maze. The EPM (Campden EPM 1000M) consists of two open arms $(10 \mathrm{~cm}$ in width and $50 \mathrm{~cm}$ in length) and two enclosed arms $(10 \mathrm{~cm}$ in width, $50 \mathrm{~cm}$ in length and $40 \mathrm{~cm}$ in height), elevated $50 \mathrm{~cm}$ above the floor. The EPM was cleaned with $70 \%$ ethanol before the start of every trial. After attachment of the stimulation cable to the connector of the rat, the animal was stimulated in its home cage for $10 \mathrm{~min}$. Subsequently, the experimenter put the rat on the centre square of the EPM facing the same open arm for every trial. The animal was allowed to explore the EPM for 5 min while being stimulated and movement was being recorded using a video camera (Ikegami, Ikegami Electronics, Neuss, Germany). After a total of 15 min of stimulation, the rat was decoupled and transported back in its home cage. Video data were analysed with Ethovision XT6 or XT7 (Noldus Information Technology, Wageningen, The Netherlands). Entry of all the three marking points (nose, centre and base of the tail) into an arm was scored as an event.

Vogel conflict task. In the second week of experimentation, rats were placed on water restriction, allowing $1 \mathrm{~h}$ of drinking per day between 1300 and 1400 hours. On the eighth, ninth and tenth day, the animals were transported to a separate room to participate in a 15-min experiment. These experiments were performed between 0900 and 1300 hours. The animals were coupled to the stimulation cable and placed in a MED modular test chamber $(30 \mathrm{~cm}$ in length, $22 \mathrm{~cm}$ in width and $50 \mathrm{~cm}$ in height), which was equipped with a water bottle of which the spout extended $2 \mathrm{~cm}$ into a drinking cavity. The number of licks was registered by a lick-o-meter (MED ENV 250, St Albans, VT, USA). The floor consisted of a grid, which was connected to a MED interface including a controlled shock source (MED ENV 413). A transparent Plexiglas screen was used to separate the part of the test chamber containing the water bottle from the rest of the chamber. On the eighth day, the rats were allowed to explore the test chamber and find the spout. On the ninth day, they underwent the adaptation test to establish a baseline drinking level over a period of $5 \mathrm{~min}$. Rats were again connected to the stimulation cable and put in the test chamber. Once the $10 \mathrm{~min}$ of stimulation had passed, the Plexiglas screen was lifted for $5 \mathrm{~min}$ in which they could drink while receiving stimulation. Subsequently, the rats were disconnected and returned to their home cage having received a total of $15 \mathrm{~min}$ of stimulation. On the tenth day, the VCT was performed. The procedure was the same as during the adaptation test except a single shock of $0.35 \mathrm{~mA}$ was delivered to the rat after every twentieth lick.

Histological examination. After completion of the experiment, all rats were given an electrolytic lesion by passing $100 \mu \mathrm{A}$ of direct current for $20 \mathrm{~s}$ to allow subsequent localization of the electrode tip. One day after lesioning, rats were killed and their brains were removed and frozen. Coronal sections of $30 \mu \mathrm{m}$ were cut on a cryostat and stained with Thionin blue or Cresyl violet for determination of the exact location of the two electrodes.

Data analysis. Data are reported as mean \pm s.e.m. The data of the EPM and VCT were analysed for stimulation 
(sham, 200 and $300 \mu \mathrm{A}$ ) effects using one-way analysis of variance (ANOVA). P-values below 0.05 (significant) or between 0.05 and 0.10 (a trend) were followed-up with a Dunnett post hoc test. Behavioural measurements of animals on the EPM were scored by dividing the number of open-arm entries by the number of closed-arm entries to acquire the ratio of open-arm entries ( $\mathrm{RO})$. The time spent on the open arms was divided by the time on the closed arms to acquire the percentage of time spent on the open arms (\%TO). The centre square was not used for the analyses. Animals were considered to be in an arm when an area from the tip of the head to the base of the tail passed into an arm. The VCT data were analysed for the amount of licks during the Adaptation session and the VCT.

\section{Results}

Histology. Animals were included in the data analysis when histological examination showed correct bilateral placement of the electrodes in the target areas (Figure 1). Eight animals were excluded from the EPM test because of practical problems with either the video recording, the stimulation wire or when rats fell off the EPM during the test session. Owing to technical problems with the VCT, the animals used for data analysis in the VCT in the NAc core and some in the NAc shell group are different from the animals used in the activity test and EPM test. However, all animals underwent all three behavioural tests. Twenty-one animals were excluded from the data analysis of the VCT in the BNST/IC and CAU group. This was caused by rats either not approaching the water bottle during the adaptation or the VCT, losing their head caps or incorrect stimulation settings.

NAc core. For the EPM, one-way ANOVAs showed no significant effect of stimulation with $200 \mu \mathrm{A}$ (seven rats) or $300 \mu \mathrm{A}$ group (eight rats) on the RO (Supplementary Figure S2), \%TO and distance moved (Supplementary Figure S3) on EPM compared with control (eight rats). Second, there was no significant effect for the NAc core $200 \mu \mathrm{A}$ group (7 rats) or the NAc core $300 \mu \mathrm{A}$ group (8 rats) on the total number of licks during the adaptation test (Supplementary Figure S4) or the VCT compared with control (11 rats).

NAc shell. One-way ANOVAs did not reveal a significant effect for the RO, \%TO and distance moved on the EPM between the control group (nine rats), the $200 \mu \mathrm{A}$

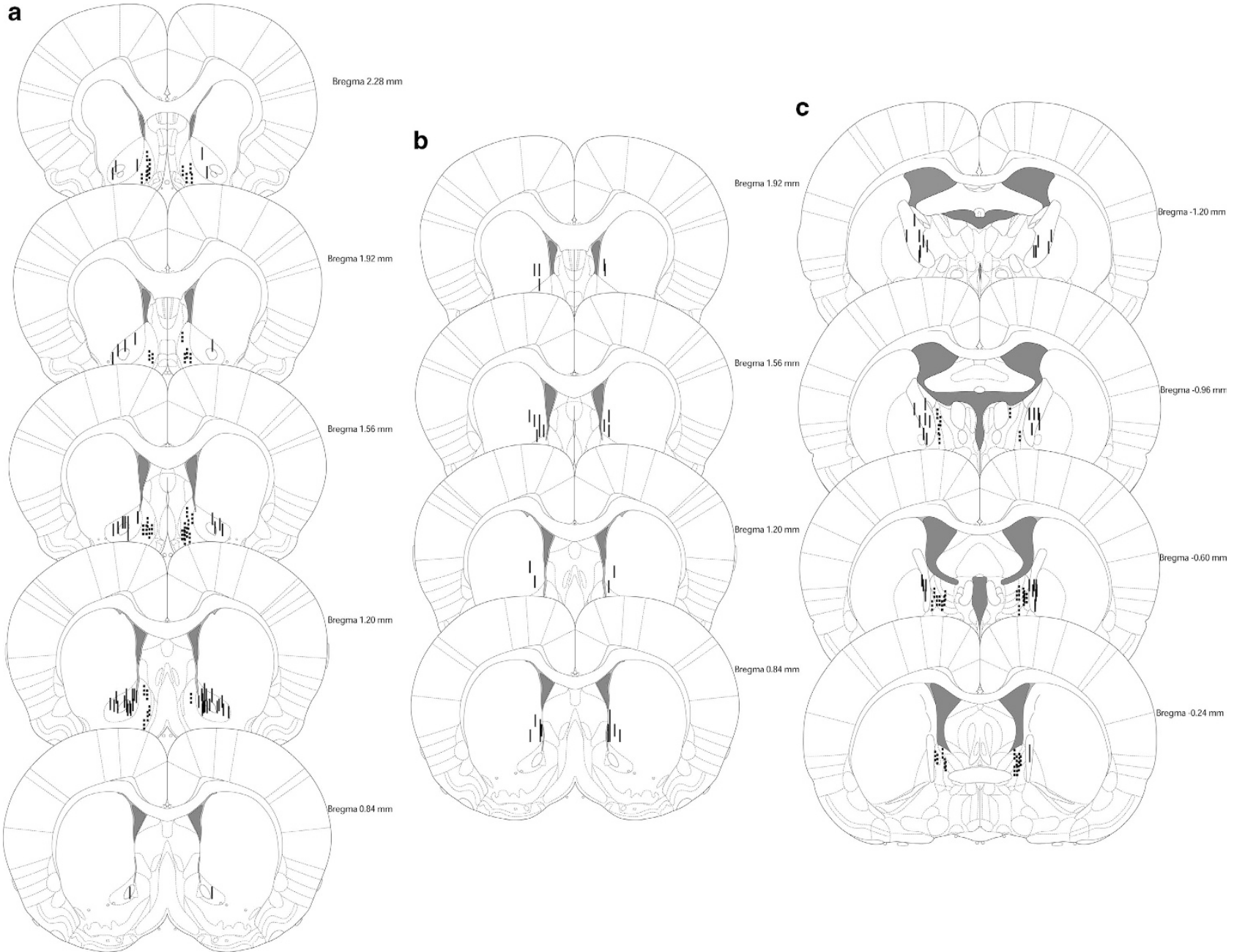

Figure 1 Histology of the included animals. Localization of the electrodes in panel a in the NAc core, NAc shell, (b) CAU and (c) BNST, IC. 

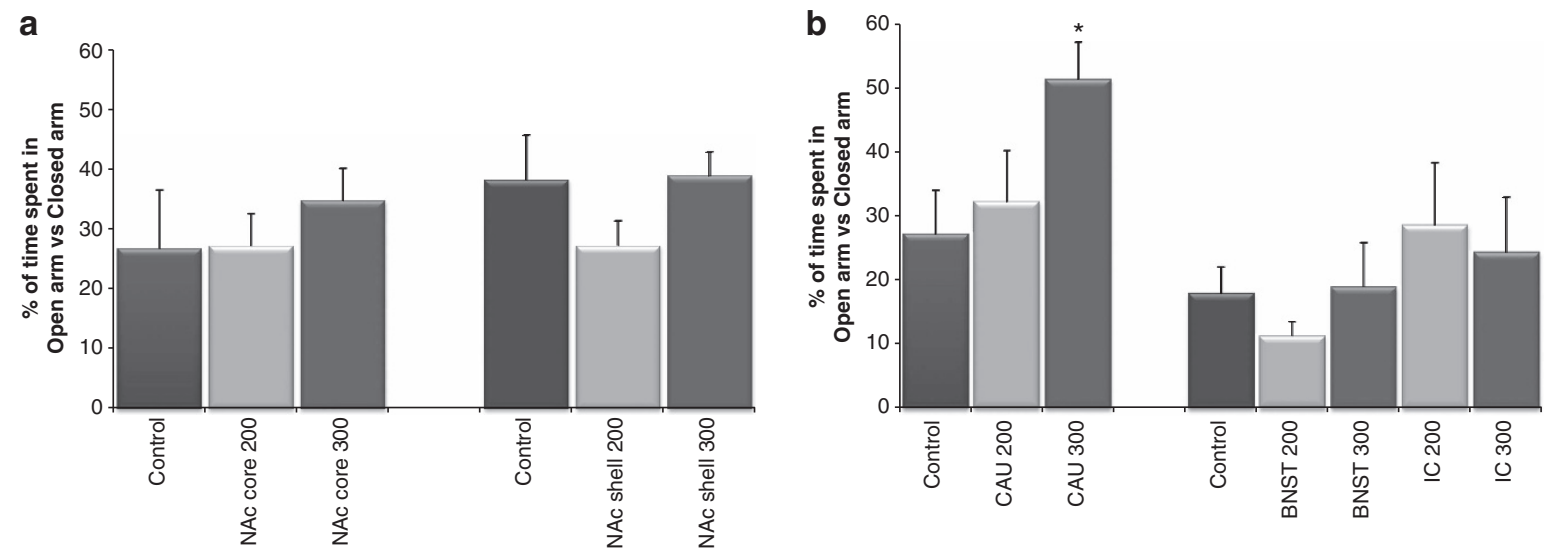

Figure 2 (a) Effect of high-frequency stimulation in the nucleus accumbens (NAc) core and NAc shell on time spent in the open arm versus the closed arm in the elevated plus maze (EPM) test. (b) Effect of high-frequency stimulation in the bed nucleus of the stria terminalis (BNST), internal capsule (IC) and caudate nucleus (CAU) on time spent in the open arm versus the closed arm in the EPM test. ${ }^{*} P<0.05$ compared with control.

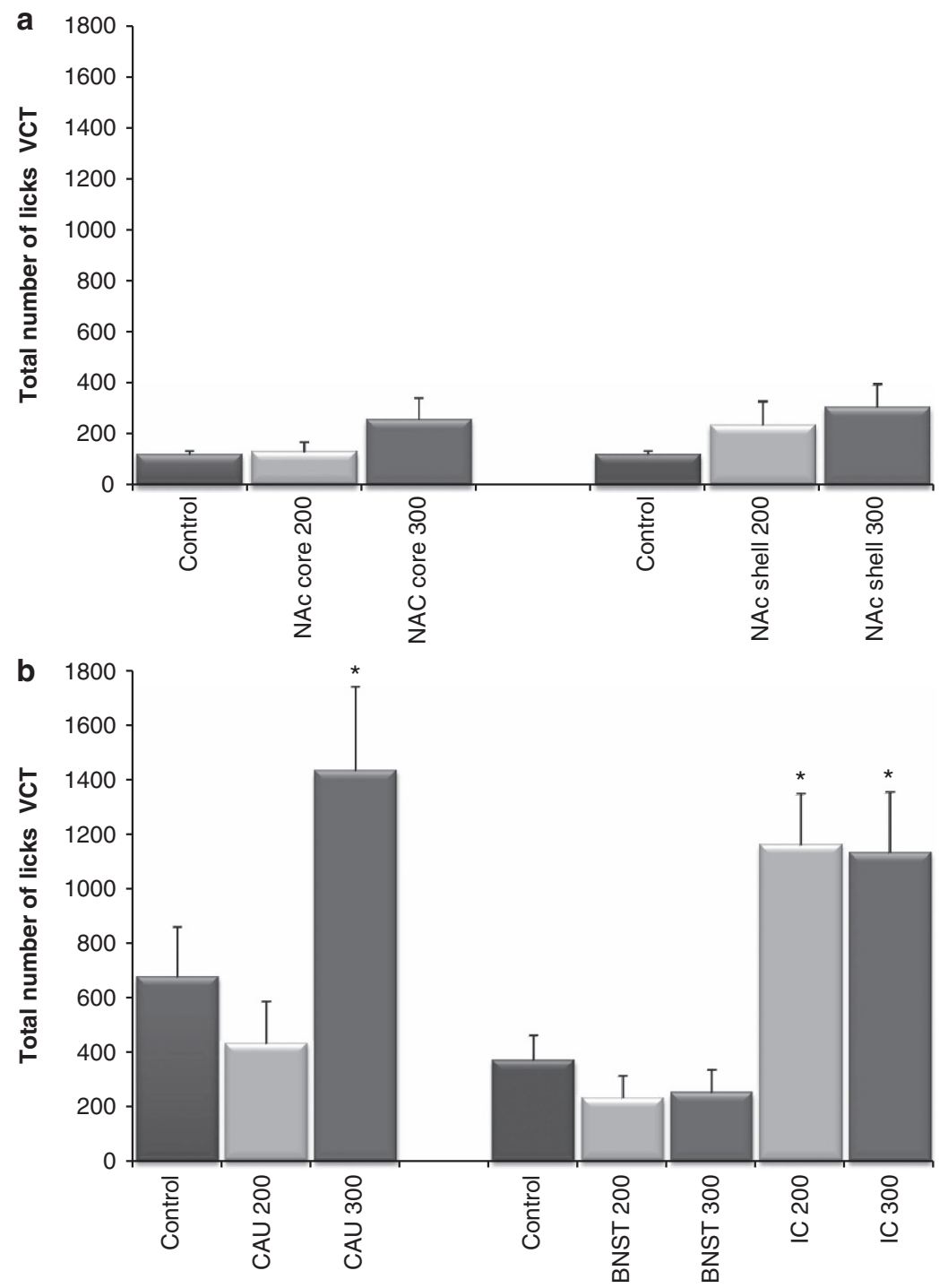

Figure 3 (a) Effect of high-frequency stimulation in the nucleus accumbens (NAc) core and NAc shell on the number of licks during the Vogel conflict test (VCT). (b) Effect of high-frequency stimulation in the bed nucleus of the stria terminalis (BNST), internal capsule (IC) and caudate nucleus (CAU) on the number of licks during the VCT. ${ }^{*} P<0.05$ compared with control. 
(seven rats) and the $300 \mu \mathrm{A}$ (eight rats) group. Stimulation of $200 \mu \mathrm{A}$ (6 rats) or $300 \mu \mathrm{A}$ (10 rats) had no significant effect on the total number of licks during the adaptation test or the VCT compared with control (11 rats).

Bed nucleus of the stria terminalis/internal capsule. There were no significant differences for the RO, \% TO and distance moved on EPM between the control group (15 rats), the BNST $200 \mu \mathrm{A}$ group (8 rats), the BNST $300 \mu \mathrm{A}$ group (8 rats), the IC $200 \mu \mathrm{A}$ group (9 rats) or the IC $300 \mu \mathrm{A}$ group (10 rats). One-way ANOVAs revealed a significant effect of stimulation on the total number of licks during the VCT $(F(4,37)=10.350, P<0.001)$ but not for the adaptation test. The total amount of licks during the VCT significantly increased in the IC $200 \mu \mathrm{A}$ group (7 rats, $P=0.001$ ) and the IC $300 \mu \mathrm{A}$ group (7 rats, $P=0.001$ ) but not in the BNST 200 (7 rats) or the BNST $300 \mu \mathrm{A}$ group (6 rats) compared with control (15 rats).

Caudate nucleus. When comparing the EPM results for the $200 \mu \mathrm{A}$ group (10 rats) and $300 \mu \mathrm{A}$ group (10 rats) to control (10 rats), one-way ANOVAs showed a trend for \%TO $(\mathrm{F}(2,27)=3.327, P=0.051)$ but not for the $\mathrm{RO}$ or distance moved. A Dunnett post hoc analysis showed a significant effect for \%TO for the $300 \mu \mathrm{A}$ group $(P=0.039)$ compared with control. A significant effect of stimulation was found on the total number of licks during the $\operatorname{VCT}(\mathrm{F}(2,21)=5.833, P=0.010)$ but not for the adaptation test. There was an anxiolytic effect for the $300 \mu \mathrm{A}$ group (6 rats, $P=0.043$ ) on the total amount of licks during the VCT compared with control (8 rats) but not for the $200 \mu \mathrm{A}$ group (10 rats; Figures 2 and 3).

\section{Locomotor activity. See Supplementary Material.}

\section{Discussion}

We investigated the effect of stimulation in two anxiety, and one activity model in five different brain regions of the rat. Stimulation of the CAU decreased both conditioned and unconditioned anxiety, and stimulation of the IC uniquely conditioned anxiety. Neither NAc nor BNST stimulation affected conditioned or unconditioned anxiety. Locomotor activity increased with NAc core stimulation but decreased with stimulation of the BNST (Supplementary Figure S1). These findings show that (1) stimulation has a differential effect on unconditioned and conditioned anxiety depending on the stimulation area, and that (2) stimulation of the IC exclusively reduced conditioned anxiety. These findings, when translated to humans, suggest that the anxiolytic effects of DBS seen in OCD patients may not be induced by stimulation of the NAc, but rather by the IC (Table 2).

Stimulation of the CAU decreases unconditioned anxiety as measured in the EPM test and conditioned anxiety as measured in the VCT. There is currently limited preclinical research available of the role of the CAU in anxiety. However, Rodriguez-Romaguera et al. ${ }^{11}$ demonstrated that stimulation at the border of the NAc and the CAU enhanced the extinction of conditioned fear using an auditory fear-conditioning paradigm. We found an anxiolytic effect of CAU stimulation in the VCT, which is comparable to the conditioning phase of the
Table 2 Overview of the results

\begin{tabular}{lccc}
\hline & Activity & Unconditioned anxiety & Conditioned anxiety \\
\hline NAc core & - & - & - \\
NAc shell & - & - & - \\
CAU & - & $\sqrt{-}$ & - \\
BNST & $\sqrt{n}$ & - & $\downarrow$ \\
IC & $\sqrt{-}$ & &
\end{tabular}

Abbreviations: ANOVA, analysis of variance; BNST, bed nucleus of the stria terminalis; CAU, caudate nucleus; IC, internal capsule; NAc, nucleus accumbens.

Black arrows indicate a $P<0.05$ for both the ANOVA as the Dunnett post hoc test. White arrows indicate a $P<0.1$ for either the ANOVA or the Dunnett post hoc test.

auditory fear-conditioning paradigm. Both these findings suggest that the CAU may have a role in conditioned anxiety in rodents. Although clinical evidence for a direct link between the CAU and anxiety is currently lacking, imaging studies consistently show abnormalities of the CAU in OCD. ${ }^{12-16}$ Moreover, Aouizerate et al. ${ }^{17}$ showed that DBS of the CAU markedly improved anxiety symptoms in one OCD patient. To conclude, our results suggest a role for the CAU as stimulation target for decreasing unconditioned as well as conditioned anxiety.

Stimulation in the anterior part of the IC had an anxiolytic effect on conditioned but not on unconditioned anxiety. To our knowledge, this is the first preclinical study that investigates the impact of stimulation on anxiety in the IC. In clinical practice, electrodes targeted at the NAc and ventral striatum/ ventral capsule region have been shown to have the most optimal responder rate when the contact points of the electrode in the IC are activated. ${ }^{18}$ Moreover, clinical experience suggests that the anxiolytic effect of DBS in OCD patients solely affects the OCD-related conditioned anxiety that is the subject of obsessions and compulsion and not the general, unconditioned anxiety. This suggests that stimulation of the IC has a unique anxiolytic effect on conditioned anxiety, and corroborates the hypothesis that the effect of DBS is due to activation of axonal fibres running through the ventral part of the IC. ${ }^{19}$ In rodents, the anterior most part of the IC is absent and the $\mathrm{IC}$ is visible only at a more posterior position, separating the BNST and the globus pallidus. Stimulation of cortico-fugal tracts running along the IC may affect the prefrontal cortex, which is known to be involved in anxiety ${ }^{20}$ and in controlling anxiety and conditioned fear. ${ }^{21-23}$ Although indirect evidence, RodriguezRomaguera et al. ${ }^{11}$ showed in rats that stimulation of the $\mathrm{CAU}$ increased cell plasticity in the medial prefrontal cortex as well as the orbitofrontal cortex. This may be due to activation of white matter fascicules that are running through the CAU and are part of the cortico-fugal fibre bundles. To summarize, our findings show a clear link between stimulation of the IC and a decrease of conditioned anxiety, which may explain the anxiolytic effects observed in OCD patients with activation of electrodes in the IC targeted at the NAc.

The absence of anxiolytic effects of BNST and NAc stimulation in the EPM test as well as the VCT is surprising. The lack of effect in the BNST, which anatomically is located near to the IC demonstrates that the effect of stimulation is 
highly localized. Although inconsistent, some studies using c-fos expression, local pharmacological injections or lesions show involvement of the NAc shell and the BNST in the EPM test. ${ }^{20,24-31}$ Although these studies suggest that manipulation of the NAc and the BNST may have an anxiolytic effect, our study clearly shows that electrical stimulation of these two areas does not. The lack of effect in our study may be related to the use of different anxiety paradigms. The BNST, for example, is more associated with chronic, slower-onset, longer-lasting sustained anxiety, ${ }^{32,33}$ whereas the EPM and VCT both measure more acute forms of anxiety. It would be of interest to assess the effects of stimulation targeted at the BNST in paradigms that produce more long-term anxiety, such as contextual conditioning. ${ }^{34}$

There are some limitations and possible confounding factors in the EPM test as well as in the VCT. First, we observed that stimulation may affect locomotor activity, which can have an impact on the outcome measurements in the EPM. However, measurements of total distance moved during the EPM test (reflecting locomotor activity) were not influenced by stimulation in any of the five target areas (Supplementary Figure S3). Therefore, the effect of stimulation in the CAU in the EPM test cannot be explained by effects on locomotor activity and reflects a decrease in unconditioned anxiety. Second, it could be suggested that the effect measured in the VCT is not an anxiolytic effect but is due to a change in pain sensitivity or an increased motivation to drink. However, rats treated with morphine, in a dose that significantly increased the pain threshold, did not show an increase in licks in the VCT, which contradicts that an increase in punished licks is due to an analgesic effect. ${ }^{35,36}$ Several studies reported that there is no effect on the number of licks when the rats have an extended water deprivation and are thus more motivated to drink. ${ }^{35,37}$ Our results show no effect of stimulation on the number of licks during the adaptation phase, which corroborates these findings. Hence, the effect of stimulation cannot be explained by variations in nociceptive threshold or motivation to drink but can be ascribed to a selective anxiolytic effect of stimulation in the IC and the CAU on conditioned anxiety. Third, we report effects in rats that were stimulated $10 \mathrm{~min}$ before and during the behavioural tests. It could be suggested that chronic stimulation might have resulted in a different effect. However, the effect of DBS on anxiety in patients is acute and can be seen within minutes after the onset of stimulation and is maintained as long as the stimulation continues. Finally, a notable difference is the variation between the control groups during the VCT (control group CAU compared with control group NAc). The animals used for the NAc core and NAc shell group came from a different supplier than the CAU group. The variations between the control groups can be caused by difference in experimenters but are more likely to be due to the different origin of the animals.

In conclusion, DBS in OCD patients has shown to have very rapid effects on anxiety. However, neither the type of anxiety nor the precise target has been elucidated in the clinical trials. Although the present studies were carried out in rats, the results indicate that depending on the precise target, different types of anxieties may be attenuated. Our findings, extrapolated to humans, suggest that the anxiolytic effect of DBS seen in OCD patients is due to stimulation of the IC and/or the CAU and not the target area the NAc. These results may help to identify the best target for DBS effects on fear and anxiety.

\section{Conflict of interest}

The authors declare no conflict of interest.

Acknowledgements. We thank Ruben Verhagen and Judith van der Heijden for their contribution to the work presented in this article.

1. Denys $\mathrm{D}$,, Mantione $\mathrm{M}$, Figee $\mathrm{M}$, van den Munckhof $\mathrm{P}$, Koerselman $\mathrm{F}$, Westenberg $\mathrm{H}$ et al. Deep brain stimulation of the nucleus accumbens for treatment-refractory obsessivecompulsive disorder. Arch Gen Psychiatry 2010; 67: 1061-1068.

2. Gabriels L, Cosyns P, Nuttin B, Demeulemeester H, Gybels J. Deep brain stimulation for treatment-refractory obsessive-compulsive disorder: psychopathological and neuropsychological outcome in three cases. Acta Psychiatr Scand 2003; 107: 275-282.

3. Greenberg BD,, Gabriels LA, Malone DA Jr, Rezai AR, Friehs GM, Okun MS et al. Deep brain stimulation of the ventral internal capsule/ventral striatum for obsessive-compulsive disorder: worldwide experience. Mol Psychiatry 2010; 15: 64-79.

4. Belzung $C$, Griebel $G$. Measuring normal and pathological anxiety-like behaviour in mice: a review. Behav Brain Res 2001; 125: 141-149.

5. Gross CT, Canteras NS. The many paths to fear. Nat Rev Neurosci 2012; 13: 651-658.

6. Millan MJ. The neurobiology and control of anxious states. Prog Neurobiol 2003; 70 : 83-244.

7. Pellow S, Chopin P, File SE, Briley M. Validation of open: closed arm entries in an elevated plus-maze as a measure of anxiety in the rat. J Neurosci Methods 1985; 14: 149-167.

8. Vogel JR, Beer B, Clody DE. A simple and reliable conflict procedure for testing antianxiety agents. Psychopharmacologia 1971; 21: 1-7.

9. van Dijk A, Mason O, Klompmakers AA, Feenstra MG, Denys D. Unilateral deep brain stimulation in the nucleus accumbens core does not affect local monoamine release. $J$ Neurosci Methods 2011; 202: 113-118.

10. Paxinos G, Watson C. The Rat Brain in Stereotaxic Coordinates. 3 edn Academic Press: San Diego, CA, USA, 2007.

11. Rodriguez-Romaguera J, Do Monte FH, Quirk GJ. Deep brain stimulation of the ventral striatum enhances extinction of conditioned fear. Proc Natl Acad Sci USA 2012; 109: 8764-8769.

12. Adams KH, Hansen ES, Pinborg LH, Hasselbalch SG, Svarer C, Holm S et al. Patients with obsessive-compulsive disorder have increased 5-HT2A receptor binding in the caudate nuclei. Int J Neuropsychopharmacol 2005; 8: 391-401.

13. Breiter HC, Rauch SL, Kwong KK, Baker JR, Weisskoff RM, Kennedy DN et al. Functional magnetic resonance imaging of symptom provocation in obsessive-compulsive disorder. Arch Gen Psychiatry 1996; 53: 595-606.

14. Lucey JV, Costa DC, Busatto G, Pilowsky LS, Marks IM, Ell PJ et al. Caudate regional cerebral blood flow in obsessive-compulsive disorder, panic disorder and healthy controls on single photon emission computerised tomography. Psychiatry Res 1997; 74: 25-33.

15. Rauch SL, Jenike MA, Alpert NM, Baer L, Breiter HC, Savage CR et al. Regional cerebral blood flow measured during symptom provocation in obsessive-compulsive disorder using oxygen 15-labeled carbon dioxide and positron emission tomography. Arch Gen Psychiatry 1994; 51: 62-70.

16. Whiteside SP, Port JD, Deacon BJ, Abramowitz JS. A magnetic resonance spectroscopy investigation of obsessive-compulsive disorder and anxiety. Psychiatry Res 2006; 146 137-147.

17. Aouizerate B, Cuny E, Martin-Guehl C, Guehl D, Amieva H, Benazzouz A et al. Deep brain stimulation of the ventral caudate nucleus in the treatment of obsessive-compulsive disorder and major depression. Case report. J Neurosurg 2004; 101: 682-686.

18. de Koning PP, Figee M, van den Munckhof P, Schuurman PR, Denys D. Current status of deep brain stimulation for obsessive-compulsive disorder: a clinical review of different targets. Curr Psychiatry Rep 2011; 13: 274-282.

19. Lehman JF, Greenberg BD, Mclntyre CC, Rasmussen SA, Haber SN. Rules ventral prefrontal cortical axons use to reach their targets: implications for diffusion tensor imaging tractography and deep brain stimulation for psychiatric illness. J Neurosci 2011; 31: 10392-10402.

20. Duncan GE, Knapp DJ, Breese GR. Neuroanatomical characterization of Fos induction in rat behavioral models of anxiety. Brain Res 1996; 713: 79-91.

21. de Visser $L$, Baars AM, van 't KJ, van den Bos R. Transient inactivation of the medial prefrontal cortex affects both anxiety and decision-making in male wistar rats. Front Neurosci 2011; 5: 102.

22. Graham BM, Milad MR. The study of fear extinction: implications for anxiety disorders. Am J Psychiatry 2011; 168: 1255-1265.

23. Kim MJ, Gee DG, Loucks RA, Davis FC, Whalen PJ. Anxiety dissociates dorsal and ventral medial prefrontal cortex functional connectivity with the amygdala at rest. Cereb Cortex 2011; 21: 1667-1673. 
24. da Cunha IC de Nazareth AM, Vargas JC, Ferraz A, Neto JM, Paschoalini MA et al. The microinjection of AMPA receptor antagonist into the accumbens shell failed to change food intake, but reduced fear-motivated behaviour in free-feeding female rats. Behav Brain Res 2008; 193: 243-247.

25. Gomes FV, Resstel LB, Guimaraes FS. The anxiolytic-like effects of cannabidiol injected into the bed nucleus of the stria terminalis are mediated by $5-\mathrm{HT} 1 \mathrm{~A}$ receptors. Psychopharmacology (Berl) 2011; 213: 465-473.

26. Horsley RR, Norman C, Cassaday HJ. Lesions of the nucleus accumbens shell can reduce activity in the elevated plus-maze. Prog Neuropsychopharmacol Biol Psychiatry 2007; 31 906-914.

27. Muigg P, Scheiber S, Salchner P, Bunck M, Landgraf R, Singewald N. Differential stressinduced neuronal activation patterns in mouse lines selectively bred for high, normal or low anxiety. PLoS One 2009; 4: e5346.

28. Sahuque LL, Kullberg EF, Mcgeehan AJ, Kinder JR, Hicks MP, Blanton MG et al. Anxiogenic and aversive effects of corticotropin-releasing factor (CRF) in the bed nucleus of the stria terminalis in the rat: role of CRF receptor subtypes. Psychopharmacology (Berl) 2006; 186: 122-132.

29. Silveira MC, Sandner G, Graeff FG. Induction of Fos immunoreactivity in the brain by exposure to the elevated plus-maze. Behav Brain Res 1993; 56: 115-118.

30. Treit $\mathrm{D}$, Aujla $\mathrm{H}$, Menard J. Does the bed nucleus of the stria terminalis mediate fear behaviors? Behav Neurosci 1998; 112: 379-386.

31. Waddell J, Morris RW, Bouton ME. Effects of bed nucleus of the stria terminalis lesions on conditioned anxiety: aversive conditioning with long-duration conditional stimuli and reinstatement of extinguished fear. Behav Neurosci 2006; 120: 324-336.
32. Davis $M$, Walker DL, Miles L, Grillon C. Phasic vs sustained fear in rats and humans: role of the extended amygdala in fear vs anxiety. Neuropsychopharmacology 2010; 35: 105-135.

33. Walker DL, Toufexis DJ, Davis M. Role of the bed nucleus of the stria terminalis versus the amygdala in fear, stress, and anxiety. Eur J Pharmacol 2003; 463: 199-216.

34. Luyten L, Casteels C, Vansteenwegen D, van Kuyck K, Koole M, Van Laere K et al. Micropositron emission tomography imaging of rat brain metabolism during expression of contextual conditioning. J Neurosci 2012; 32: 254-263.

35. Agmo A, Pruneda R, Guzman M, Gutierrez M. GABAergic drugs and conflict behavior in the rat: lack of similarities with the actions of benzodiazepines. Naunyn Schmiedebergs Arch Pharmacol 1991; 344: 314-322.

36. Basso AM, Gallagher KB, Mikusa JP, Rueter LE. Vogel conflict test: sex differences and pharmacological validation of the model. Behav Brain Res 2011; 218: 174-183.

37. Tonetto LL, Terzian AL, Del Bel EA, Guimaraes FS, Resstel LB. Inhibition of the NMDA receptor/nitric oxide pathway in the dorsolateral periaqueductal gray causes anxiolytic-like effects in rats submitted to the Vogel conflict test. Behav Brain Funct 2009; 5: 40.

(c) (i) () $\Theta$ Translational Psychiatry is an open-access journal published by Nature Publishing Group. This work is licensed under a Creative Commons Attribution-NonCommercialNoDerivs 3.0 Unported License. To view a copy of this license, visit http://creativecommons.org/licenses/by-nc-nd/3.0/

Supplementary Information accompanies the paper on the Translational Psychiatry website (http://www.nature.com/tp) 